UDC 34:336.711(470+571)

LBC 67.404.212

\title{
THE LEGAL REGULATION OF THE NATIONAL PAYMENT SYSTEM BY THE BANK OF RUSSIA
}

\author{
Galina A. Gavrikova \\ Volgograd State University, Volgograd, Russian Federation; \\ Department of Corporate Management of MUS Energetiki JSC, Moscow, Russian Federation
}

Introduction: the author examines the legal status of the Bank of Russia under the Federal law of 27.06.2011 № 161-FZ “On National Payment System”, namely, the requirements of the Bank of Russia for operators conducting money transfers, including the electronic transfers, for banking payment agents, and sub-agents, carrying out transfers of funds by order of the payer or recipient issued under non-cash payments. Purpose: to study the regulation of the national payment system by the Bank of Russia, taking into account the Federal Laws "On National Payment System", "On the Central Bank of the Russian Federation". Methods: the methods of scientific knowledge and system approach, allowing to manage risks in the payment system and to carry out forecasting activity are investigated. The historical component. Results: the powers granted to the Bank of Russia in accordance with the regulations allow the Bank of Russia to carry out certain activities and procedures aimed at providing the functional support and reducing the risks when conducting money transfers by operators of the payment system. Conclusions: the legal regulation of the payment system by the Bank of Russia allows ensuring the monitoring and prompt adoption of measures for the systemically and socially important payment systems, to develop the financial market, and to conduct without problems the payments of money with smaller risks, both for operators of the payment system, and for physical persons.

Key words: national payment system, the Bank of Russia, payment system operators, systemically important payment system, socially important payment system.

УДК 34:336.711(470+571)

ББК 67.404 .212

\section{ПРАВОВОЕ РЕГУЛИРОВАНИЕ БАНКОМ РОССИИ НАЦИОНАЛЬНОЙ ПЛАТЕЖНОЙ СИСТЕМЫ}

\section{Галина Александровна Гаврикова}

Волгоградский государственный университет, г. Волгоград, Российская Федерация;

Департамент корпоративного управления АО «МУС Энергетики», г. Москва, Российская Федерация

Введение: автор исследует правовой статус Банка России в рамках Федерального закона от 27.06.2011 № 161-Ф3 «О национальной платежной системе», а именно, требования Банка России к операторам, осуществляющим переводы денежных средств, в том числе электронных, банковским платежным агентам, субагентам, осуществлящим переводы денежных средств по распоряжению плательщика или получателя, оформленных в рамках безналичных расчетов. Цель: изучить регулирование Банком России национальной платежной системы с учетом Федеральных законов «О национальной платежной системе», «О Центральном банке Российской Федерации». Методы: исследованы методы научного познания и системного $\infty$ подхода, позволяющие управлять рисками в платежной системе, осуществлять прогнозирование. Истори군 ческая составляющая. Результаты: полномочия, предоставленные Банку России в соответствии с норма\& тивными актами, позволяют Банку России проводить определенные мероприятия и процедуры, направленных на функциональное обеспечение и снижение рисков при проведении переводов денежных средств операторами платежной системы. Выводы: правовое регулирование Банком России платежной системы позволяет обеспечить наблюдение и оперативное принятие мер по системно и социально значимым пла养 тежным системам, развивать финансовый рынок, беспроблемно осуществлять проведение денежных средств (2) $\mathrm{C}$ 
Ключевые слова: национальная платежная система, Банк России, операторы платежной системы, системно-значимая платежная система, социально-значимая платежная система.

\section{Введение}

С принятием Федерального закона «О национальной платежной системе», на Банк России были возложены полномочия по организации правового обеспечения и наблюдения за функционированием платежной системы.

Банк России является центром, через который проходит платежный оборот различных хозяйствующих субъектов. Через платежную систему Банка России реализуется денежнокредитная и бюджетная политика России. В связи с наделением Банка России особыми полномочиями по денежно-кредитной политике, Банку России был присвоен особый конституционно-правовой статус, который прописан в ст. 75 Конституции РФ (осуществление денежной эмиссии), а в качестве основной функции защита и обеспечение устойчивости рубля [1].

Надо отметить, что Банк России не является органом государственной власти, вместе с тем его полномочия по своей правовой структуре относятся к функциям государственной власти, так как их реализация предполагает применение мер государственного принуждения. Функции и полномочия, предусмотренные Конституцией РФ и Федеральным законом «О Центральном банке Российской Федерации (Банке России)» Банк России осуществляет независимо от федеральных органов государственной власти, органов государственной власти субъектов РФ и органов местного самоуправления.

Чтобы понять, почему государство наделило Банк России единоличными полномочиями по наблюдению, обеспечению функционального развития национальной платежной системы и осуществлению надзора за деятельностью субъектов, обеспечению стабильности рубля, необходимо обратиться к истокам развития Банка.

\section{Предыстория развития Банка России}

Полномочия Банка России, как Государственного банка, относятся к периоду существования Российской империи, где банк осуществлял обслуживание счетов бюджета. Пос- ле проведения бюджетной реформы в 1869 году, ряд полномочий по кассовому исполнению бюджета были переданы Государственному банку Российской империи. В этот период произошло слияние кассовой наличности Государственного казначейства и оборотной наличности Государственного банка, что способствовало оперативному обороту денежных средств государства, в котором существовало главное кредитное управление в качестве Государственного банка, тем самым государство сохраняло контроль над денежным оборотом бюджетных средств. Государственный банк осуществлял данную функцию путем депонирования на беспроцентном текущем счете бюджетных средств, в результате которого становился плательщиком по отношению к казначейским органам. В 1917 году банковская система Российской империи была одной из самых богатых и развитых в мире. Функционировали коммерческие, сберегательные, инвестиционные, ипотечные банки и ряд организаций. В конце 1917 года был принят декрет о национализации банков, которым банковское дело объявлялось государственной монополией, а все существовавшие частные банки и банкирские конторы подлежали объединению с Государственным банком с полной конфискацией капиталов бывших частных банков. В последующем, при проведении банковской реформы и принятии закона «О Центральном банке России», была отрегулирована общая денежная политика банка и регулирование деятельности кредитных и не кредитных финансовых организаций.

\section{Функциональные возможности Банка России}

Функциональные возможности информационно-аналитической системы Банка России позволяют управлять рисками в платежной системе, осуществлять прогнозирование устойчивости отдельных участников расчетов и их групп, прогнозировать динамику поведения отдельных участников и системы в целом, осуществлять поиск механизмов и схем для выхода из кризисных ситуаций. Принятый 
Федеральный закон от 27.06.2011 № 162-Ф3 «О внесении изменений в отдельные законодательные акты Российской Федерации», в связи с принятием Федерального закона «О национальной платежной системе» прописал, что Банк России организует и обеспечивает эффективное и бесперебойное функционирование платежной системы и осуществляет наблюдение за ней. Также, в соответствии с пп. 4.1 Федерального закона от 10 июля 2002 г. № 86-Ф3 «О Центральном банке Российской Федерации (Банке России)» указывается, что Банк России осуществляет надзор и наблюдение в национальной платежной системе (далее - НПС) [4].

Банк России может выступать в НПС как оператор платежной системы, оператор по переводу денежных средств, оператор услуг платежной инфраструктуры, центральный платежный клиринговый контрагент, регулятор, что позволяет Банку принимать нормативные акты, регулируя отношения в НПС.

Платежная система Банка России является основной инфраструктурой, используемой для реализации денежно-кредитной политики, поддержания и функционирования денежных и финансовых рынков. Перевод денежных средств в платежной системе осуществляется с быстрым подтверждением окончательности перевода денежных средств и возможностью незамедлительного использования денежных средств, что позволяет гарантировать своевременный допуск банковского сектора к средствам, размещенных на счетах в Банке России, тем самым способствуя поддержанию стабильности НПС [3].

Для быстрого механизма перевода денежных средств, Банк России запустил аналоговую систему SWIFT, как альтернативу каналам межбанковского взаимодействия, целью которой является обеспечение гарантированного и бесперебойного предоставления услуг по передаче электронных сообщений по финансовым операциям, снижению рисков, влияющих на безопасность и конфиденциальность оказания услуг по передаче финансовых сообщений. Услуги по передаче финансовых сообщений с использованием системы передачи финансовых сообщений, установлены Указанием Банка России от 05.10.2015 № 3814-У [2].
В соответствии с гл. 5 Федерального закона от 27.06.2011 № 161-Ф3 «О национальной платежной системе», Банк России наделен полномочиями по определению порядка осуществления и наблюдения в платежной системе, по инициированию изменений в деятельности системно и социально значимых платежных систем.

Отличительной чертой системно значимых платежных систем служит их влияние на сферу платежей, общий объем переводов денежных средств, который может вызвать системные сбои в безналичном платежном обороте, что грозит ущербом экономике в целом.

Социально значимые платежные системы относятся к розничным платежным системам, в рамках которых осуществляется большое количество переводов денежных средств на небольшие суммы, осуществляемые физическими лицами. При формировании значения общего объема переводов денежных средств, в целях признания платежной системы социально значимой, Банк России ориентируется на долю переводов денежных средств в соответствующей платежной системе по отношению к общему объему переводов денежных средств. Ст. 22 Федерального закона от 27.06.2011 № 161-Ф3 «О национальной платежной системе» определяет четыре категории признания платежной системы социально значимой, отражающие объемные и количественные характеристики проведенных физическими лицами за определенный период времени переводов денежных средств с использованием платежных карт, без открытия банковских счетов [3].

При определении значений критериев по признанию платежной системы социально значимой, Банк России, с учетом ст. 22 Федерального закона от 27.06.2011 № 161-Ф3 «О национальной платежной системе», исходит из того, что каждая категория переводов денежных средств состоит из инструментов или способов перевода, которые не являются взаимозаменяемыми, и тем самым платежные услуги платежной системы одной категории не могут быть заменены услугами платежной системы другой категории [3].

Наблюдение в НПС включает три вида деятельности Банка России:

1. Мониторинг - сбор, систематизация и анализ информации о деятельности наблюда- 
емых организаций, других субъектов национальной платежной системы и связанных с ними объектов наблюдения. Указанная деятельность дает право Центральному банку Российской Федерации запрашивать и получать от наблюдаемых организаций информацию об оказываемых ими платежных услугах, услугах платежной инфраструктуры, информационно-коммуникационных технологиях и количественных характеристиках инфраструктуры, об уровне обеспечения защиты информации при оказании платежных услуг, включая количество инцидентов, связанных с нарушениями требований к обеспечению защиты информации при осуществлении переводов денежных средств.

2. Оценка - определяет степень соответствия наблюдаемых организаций и связанных с ними объектов наблюдения. Наблюдаемые организации должны соответствовать рекомендациям Банка России, к которым относятся собственные рекомендации Банка России, рекомендации по использованию стандартов или лучшей мировой и отечественной практики, при условии их опубликования в изданиях Банка России. Банку России предоставлены полномочия по изданию методических разъяснений по использованию таких рекомендаций, информирование субъектов НПС и объектов наблюдения о результатах проведенного Банком России мониторинга их деятельности, связанной с оказанием платежных услуг, услуг платежной инфраструктуры. В действительности, рекомендации являются обязательными для выполнения.

Оценка, как вторая составляющая процедуры наблюдения, проводится для определения степени соответствия субъектов НПС рекомендациям Банка России в сфере платежных систем.

3. Инициирование изменений - подготовка по результатам указанной оценки предложений по изменению деятельности оцениваемых (наблюдаемых) организаций и связанных с ними объектов наблюдения.

Раскрытый порядок осуществления наблюдения не является полным, поскольку ч. 11 ст. 35 Федерального закона от 27.06.2011 № 161-Ф3 «О национальной платежной системе» содержит положения о том, что порядок осуществления наблюдения определяется По- ложением Банка России от 31 мая 2012 г. № 380-П «О порядке осуществления наблюдения в национальной платежной системе», где Банк России осуществляет наблюдение за деятельностью операторов по переводу денежных средств, операторов платежных систем, операторов услуг платежной инфраструктуры (наблюдаемых организаций), других субъектов национальной платежной системы за оказываемыми ими услугами, а также за развитием платежных систем, платежной инфраструктуры.

Приоритетным является наблюдение за значимыми платежными системами, которое осуществляется Банком России посредством всех видов деятельности. В отношении наблюдаемых организаций, других субъектов национальной платежной системы, платежных систем, не являющихся значимыми, а также других объектов наблюдения, Банк России осуществляет мониторинг.

Необходимо отметить, что все направленные Банком России рекомендации субъектам платежной системы являются обязательными к исполнению. Закон «О национальной платежной системе» предоставил Банку России полномочия устанавливать ряд количественных характеристик операторов по переводу денежных средств и платежных систем, позволяющих формировать субъектный состав национальной платежной системы, отвечающий потребностям социального и экономического развития России. Одним из таких требований, прописанных в ст. 16 Федерального закона от 27.06.2011 № 161-Ф3 «О национальной платежной системе», является финансовое состояние и технологическое обеспечение, влияющие на бесперебойность функционирования платежной системы, которые должны быть объективными, доступными для публичного ознакомления и обеспечивать равноправный доступ операторов услуг платежной инфраструктуры в платежную систему.

При осуществлении перевода денежных средств в рамках платежной системы, операторами по переводу денежных средств, находящимися на территории Российской Федерации, должны привлекаться операторы услуг платежной инфраструктуры, которые соответствуют требованиям Федерального закона «О национальной платежной системе», нахо- 
дятся и осуществляют все функции на территории России. Это не распространяется на случаи осуществления трансграничного перевода денежных средств.

\section{Выводы}

В соответствии с установленными правовыми связями и платежной инфраструктурой, на основе единых правил платежной системы и ее стандартов, участники расчетов и платежей могут рассчитываться по сделкам или переводам денежных средств, относящихся к разным участкам финансового рынка.

Установленная стандартная практика раскрытия информации о платежных системaх, позволяет участникам рынка платежных услуг оценивать последствия своего участия в той или иной платежной системе, в части принимаемых ими рисков, более обоснованно проводить сравнение функционирования различных платежных систем, а Банку России осуществлять мониторинг соответствия организации и функционирования платежных систем международным стандартам. Таким образом, при раскрытии информации в более широком смысле, это служит бесперебойному функционированию платежных систем и укреплению стабильности финансового рынка.

Требования, предъявляемые к принятию нормативных актов Банком России, обеспечивающих функционирование платежной системы Банка России, позволяют полагать, что правила и договоры соответствуют действующему законодательству Российской Федерации.

\section{СПИСОК ЛИТЕРАТУРЫ}

1. Конституция Российской Федерации (принята всенародным голосованием 12.12.1993) (с учетом поправок, внесенных Законами РФ о поправках к Конституции РФ от 30.12.2008 № 6-ФКЗ, от 30.12.2008 № 7-ФКЗ, от 05.02.2014 № 2-ФКЗ, от 21.07.2014 № 11-ФКЗ) // Собрание законодательства РФ. - 2014. - № 15. - Ст. 75.

2. Указание Банка России «О порядке оказания Банком России услуг по передаче финансовых сообщений кредитным организациям и их клиен- там - юридическим лицам» от 5 октября 2015 г. № 3814-У (Зарегистрировано в Минюсте России 27.11.2015 № 39876). - Доступ из справ.-правовой системы «КонсультантПлюс».

3. Федеральный закон «О национальной платежной системе» от 27.06.2011 № 161-ФЗ. - Доступ из справ.-правовой системы «КонсультантПлюс».

4. Федеральный закон «О Центральном банке Российской Федерации (Банке России)» от 10 июля 2002 г. № 86-Ф3. - Доступ из справ.-правовой системы «КонсультантПлюс».

\section{REFERENCES}

1. Konstitutsiya Rossiyskoy Federatsii (prinyata vsenarodnym golosovaniem 12.12.1993) (s uchetom popravok, vnesennykh Zakonami RF o popravkakh $\mathrm{k}$ Konstitutsii RF ot 30.12.2008 № 6-FKZ, ot 30.12.2008 № 7-FKZ, ot 05.02.2014 № 2-FKZ, ot 21.07.2014 № 11FKZ) [The Constitution of the Russian Federation (Adopted by Popular Voting on December 12, 1993) (taking into account the amendments introduced by the Legal Acts of the Russian Federation on Amendments to the Constitution of the Russian Federation no. 6-FKL, no. 7-FKL of December 30, 2008; no. 2-FKL of February 5, 2014; no. 11-FKL of July 21, 2014)]. Sobranie zakonodatelstva RF [Collected Legislation of the Russian Federation], 2014, no. 15, art. 75 .

2. Ukazanie Banka Rossii «O poryadke okazaniya Bankom Rossii uslug po peredache finansovykh soobshcheniy kreditnym organizatsiyam i ikh klientam - yuridicheskim litsam» ot 5 oktyabrya 2015 g. № 3814-U (Zaregistrirovano v Minyuste Rossii 27.11.2015 N 39876) [Instruction of the Bank of Russia "On the Procedure for Rendering Services for the Transfer of Financial Messages to Credit Institutions and Their Clients - Legal Entities by the Bank of Russia" of October 5, 2015 no. 3814-U (Registered in the Ministry of Justice of Russia on November 27, 2015 no. 39876)]. Access from Reference Legal System "KonsultantPlyus".

3. Federalnyy zakon $" O$ natsionalnoy platezhnoy sisteme» ot 27.06.2011 № 161-FZ [Federal Law "On the National Payment System" of June 27, 2011 no. 161-FL]. Access from Reference Legal System "KonsultantPlyus".

4. Federalnyy zakon "O Tsentralnom banke Rossiyskoy Federatsii (Banke Rossii)» ot 10 iyulya 2002 g. № 86-FZ [The Federal Law "On the Central Bank of the Russian Federation (Bank of Russia)" of July 10, 2002 no. 86-FL]. Access from Reference Legal System "KonsultantPlyus". 


\section{ВОПРОСЫ ЧАСТНОПРАВОВОГО РЕГУЛИРОВАНИЯ}

\section{Information about the Author}

Galina A. Gavrikova, Postgraduate Student, Department of Civil and International Private Law, Volgograd State University, Base Department of the Southern Scientific Center of the Russian Academy of Sciences, Head of Department of Corporate Management of MUS Energetiki JSC, Akademika Chelomeya St., 5A, 117630 Moscow, Russian Federation, galina.gavrikova34@yandex.ru.

\section{Информация об авторе}

Галина Александровна Гаврикова, аспирант кафедры гражданского и международного частного права, Волгоградский государственный университет, базовая кафедра ЮНЦ РАН; начальник Департамента корпоративного управления АО «МУС Энергетики», ул. Академика Челомея, 5А, 117630 г. Москва, Российская Федерация, galina.gavrikova34@yandex.ru. 